Sai Praveen Haranath
Srinivas Jakkinaboina

\section{Is proton pump inhibitor use a significant confounder for chromogranin A levels in sepsis?}

Accepted: 27 June 2012

Published online: 15 August 2012

(C) Copyright jointly held by Springer and ESICM 2012

An author's reply to this comment is available at: doi:10.1007/s00134-012-2666-1.

Dear Editor,

We read with interest the article by Røsjø et al. on chromogranin A in sepsis [1]. We believe the table on baseline characteristics has an error
[1]. The number of patients treated with proton pump inhibitors is perhaps incorrect and possibly inverted between the survivor and non-survivor groups, being printed as 138 $(83 \%)$ and $57(88 \%)$, respectively. We also wonder whether there may be other inadvertent errors in the tabulation which may impact the results. It was not clear whether there were any patients with pre-existing neuroendocrine tumors, which may affect the chromogranin A level. As noted by the authors and others [2] proton pump inhibitors increase chromogranin A levels, and because the absolute values measured were only marginally above the normal in both groups it is unclear whether the levels measured are of sufficient difference from baseline to be of clinical utility. In addition, patients who used proton pump inhibitors prior to admission were not clearly excluded or delineated in this study.

\section{References}

1. Røsjø H, Nygård S, Kaukonen KM, Karlsson S, Stridsberg M, Ruokonen E, Pettilä V, Omland T, FINNSEPSIS Study Group (2012) Prognostic value of chromogranin A in severe sepsis: data from the FINNSEPSIS study. Intensive

Care Med 38:820-829. doi: 10.1007/s00134-012-2546-8

2. Raines D, Chester M, Diebold AE, Mamikunian P, Anthony CT, Mamikunian G, Woltering EA (2012) A prospective evaluation of the effect of chronic proton pump inhibitor use on plasma biomarker levels in humans. Pancreas 41:508-511

\section{S. P. Haranath $(\bullet) \cdot$ S. Jakkinaboina} Department of Critical Care Medicine, Apollo Hospitals, Jubilee Hills, Hyderabad 500033, India e-mail: indialungdoc@gmail.com

S. Jakkinaboina e-mail: sjakkina@gmail.com 